\title{
Hormonal contraception and sexual desire: A questionnaire-based study of young Swedish women
}

\author{
Agota Malmborg, Elin Persson, Jan Brynhildsen and Mats Hammar
}

\section{Linköping University Post Print}

\section{Tweet}

N.B.: When citing this work, cite the original article.

This is an electronic version of an article published in:

Agota Malmborg, Elin Persson, Jan Brynhildsen and Mats Hammar, Hormonal contraception and sexual desire: A questionnaire-based study of young Swedish women, 2015, European journal of contraception \& reproductive health care, 1-10.

European journal of contraception \& reproductive health care is available online at informaworldTM:

http://dx.doi.org/10.3109/13625187.2015.1079609

Copyright: Taylor \& Francis: STM, Behavioural Science and Public Health Titles http://www.tandf.co.uk/journals/default.asp

Postprint available at: Linköping University Electronic Press

http://urn.kb.se/resolve?urn=urn:nbn:se:liu:diva-126286 
Hormonal contraception and sexual desire: a questionnaire-based study of young Swedish women

Agota Malmborg, Elin Persson, Jan Brynhildsen and Mats Hammar

Obstetrics and Gynecology, Department of Clinical and Experimental Medicine, Faculty of Health Sciences, Linköping University, Linköping, Sweden

Short title: Hormonal contraception and sexual desire

Correspondence: Agota Malmborg, Obstetrics and Gynecology, Department of Clinical and Experimental Medicine, Faculty of Health Sciences, Linköping University, SE-581 83 Linköping, Sweden. Tel: +46 704904891. E-mail: agota.malmborg@liu.se 


\begin{abstract}
Objectives The aim of the study was to determine whether a decrease in sexual desire is more prevalent among women using hormonal contraception than among women using hormone-free contraception, and whether a decrease increases the risk of changing to another contraceptive method.
\end{abstract}

Methods A validated questionnaire was posted to 3740 women (aged 22, 25 or 28 years) living in Sweden. Descriptive statistics were used to present the results; differences between groups were tested using $\chi^{2}$ analyses. A multiple logistic regression model was used for analysis of possible confounders.

Results The response rate was 50\%. The majority (81\%) of respondents used some kind of contraception, and $88 \%$ were generally satisfied with the method used. Regardless of the type of method, $27 \%$ of hormonal contraceptive users reported a decrease in sexual desire that they attributed to their use of hormonal contraception, whereas only $12 \%$ of women using hormone-free contraception reported a decrease in sexual desire $(p<0.01)$. This twofold risk of a decrease in sexual desire was shown in the multiple regression analysis to be independent of age group, depression, BMI, educational level and parity. However, having a partner was found to be a factor of equal importance: women with partners experienced reduced desire twice as often as women without partners. The observed odds ratio for planning to stop hormonal contraception or to change to a different type due to reduced desire was 8.16 (95\% confidence interval 6.65-10.1) among women who had had the same experience during a previous period of hormonal contraceptive use.

Conclusions Women using hormonal contraception were more likely to experience reduced sexual desire compared with women using hormone-free contraception. Experiencing reduced desire was a strong predictive factor for women to change contraceptive method.

\title{
KEYWORDS
}

Cross-sectional study; Hormonal contraception; Intrauterine contraception; Progestogen; Questionnaire; Sexual desire 


\section{INTRODUCTION}

The most common hormonal contraceptive method in the West is the combined oral contraceptive pill (COC) used by 30-60\% of women below 30 years of age $\mathrm{e}^{1,2}$. COCs offer several medical benefits in addition to providing effective contraception ${ }^{3}$, which, together with their relatively low cost, availability and convenience, have led to their being a common first-choice contraceptive.

However, overall continuation rates of COC use are low. An American prospective observational study reported a 43\% 24-month continuation rate for COC use (excluding women who wished to become pregnant $)^{4}$. A 12-month follow-up study ${ }^{5}$ found that the most common reason given for discontinuation was experience of adverse effects; other reasons given were forgetting to take pills and difficulty in obtaining a supply. A Swedish study found that psychological effects were also a factor leading to discontinuation of COC use and noted that the effects increased over time ${ }^{1}$.

While the somatic side effects of hormonal contraception (COC, progestogen-only pill [POP], and the levonorgestrel-releasing intrauterine system [LNG-IUS]) are well documented, the psychological effects on mood and sexual desire have not been as well studied ${ }^{6}$.

The nature of sexuality is complex and is influenced by many non-biological and biological factors; it is therefore difficult to reliably predict how sexual activity may be affected by different contraceptive methods ${ }^{7}$. The natural fluctuations of steroid hormones have been investigated and have been shown to modulate women's sexual activity during the menstrual cycle ${ }^{8}$. Hormones act both in the central nervous system ${ }^{9}$ and in peripheral sites important for sexual function ${ }^{10}$. Changes in concentrations of estrogen, sex hormone binding globulin and free testosterone may occur during use of the COC. These effects, together with direct progestogen effects, may affect sexual desire in some women ${ }^{8,11,12}$. Reviews that summarise the effects on sexuality of hormonal contraceptives conclude that approximately $12 \%$ of women experience an increase or decrease in sexual desire; the majority, however, are unaffected by the use of $\mathrm{COCs}^{13-15}$.

The two main objectives of this study were: first, to determine whether experiencing a decrease in sexual desire is more prevalent in women who use hormonal contraceptives 
than in women who use hormone-free alternatives, and whether statistical differences remain after adjusting for demographic factors and other possible confounders; second, to find out whether a decrease in sexual desire is a factor that leads women to discontinue hormonal contraceptive use. A secondary objective was to investigate positive side effects and extent of method satisfaction experienced by users of hormonal contraception.

\section{METHODS}

This cross-sectional questionnaire-based study was conducted in Linköping, Sweden, a university city with a mixed urban and rural population of about 150,000 inhabitants.

All of the women ( $N=3870)$ living in Linköping who, according to the population register, turned 22, 25 or 28 years between 1 January and 31 December 2013 were eligible for inclusion in the study. No other inclusion or exclusion criteria were applied.

Questionnaires were posted through the traditional mailing system in March 2013 and two reminders were sent out about 2 and 4 months later to those who had not replied. The envelopes of 130 women were returned unopened. The number of women in each of the three age groups who were reached by the questionnaire was as follows: age $22(n=1435)$, age $25(n=1268)$ and age $28(n=1037)$. Of this total of 3740 women, constituting the study population, 1851 returned completed questionnaires. No financial compensation or other incentives were handed to the participants.

The questionnaires were optically read after ensuring absolute accordance between optical and manual reading of three completed questionnaires. All questionnaires were coded to enable the reminders to be sent to the right women. To guarantee participant anonymity the coding key document was kept locked and both the codes and the key document were destroyed when optical reading was completed. Answers of a qualitative character were saved as JPEG files for manual survey.

The three-part questionnaire was compiled from pre-existing questionnaires developed by three different research teams. ${ }^{1,16,17}$ Part 1 contained questions about demographic background such as age, height, weight, smoking, exercising habits, educational level, selfestimate of overall health status, depression treatment, previous and ongoing pregnancies, the number of children each woman had had, and whether they had breast-fed their baby. Part 2 asked each participant to name her current contraceptive method and to report 
overall satisfaction with the chosen method, duration of usage, where she had received the prescription, and whether contraceptive counselling had been sought and given. Several questions asked about positive and negative side effects and whether any consideration had been given to ending use of the method or changing to a new method. Part 2 also included a question about experiences with previously used hormonal contraceptives and reasons for discontinuation. Part 3 was concerned with different aspects of sexuality. Questions were based upon the validated Female Sexual Function Index (FSFI), which is a short, multidimensional scale for assessing sexual function in women ${ }^{16}$, and the McCoy Female Sexuality Questionnaire (MFSQ) ${ }^{17}$. A separate question was added concerning changes in sexual desire experienced with the current contraceptive method. This question was phrased as: 'Do you feel that your current contraceptive method affects your sexual desire?' The response alternatives were: (1) no; (2) yes, for the worse; (3) yes, for the better; (4) I use no contraceptives. We also asked the following question about relationship status: 'What is your relationship to your present sexual partner?' The response alternatives were: (1) I have no partner; (2) husband/cohabiting partner; (3) boyfriend/girlfriend; (4) occasional partners.

The variables were, except for height and weight, nominal, pre-formulated multiple choice alternatives (3-16 alternatives in the different questions). Questions about side effects were followed by a space for personal comments.

The questionnaire was validated using comprehension testing by three volunteers and then by establishing test-retest stability after 2 weeks with eight 25 -year-old volunteers. After comprehension testing, smaller modifications of some of the questions were done. In all, 11 of 30 questions were answered slightly differently by one or more of the eight volunteers. The difference in the number of alternative steps for each of these 11 questions had a median of zero and the mean value ranged between 0.12 and 0.5 , which is why we considered the questionnaire to have reasonable test-retest stability; therefore, no additional modifications of the questions were needed.

The data were analysed using IBM SPSS statistics version 21. Results are presented as frequencies and proportions in tables and text. Comparisons of differences between groups were performed using the $\chi^{2}$ test and, when the expected count was less than five, Fischer's exact test. In order to adjust for possible confounders, we used a binary multiple logistic regression model. The significance level was set as two-tailed $p<0.05$ for all analyses. 
The study was approved by the regional ethics committee in Linköping (Dno 2013/257$31)$.

\section{RESULTS}

Of the total of 3740 women who received the questionnaire, 1851 (50\%) responded; there was a similar response rate in each of the three age groups $(p=0.23)$ Background data are presented in Table 1.

The most common contraceptive method was the COC, used by $44 \%$, followed by the POP (desogestrel), used by $12 \%$. A hormonal method was used by $60 \%$ of the total study group, and $15 \%$ used no contraception at all (pregnant and nursing women not counted). The use of different contraceptives differed between the three age groups $(p<0.05)$ (Figure 1). Using no contraception was more common in the 28-year-old group than in the two younger groups $(p=0.01)$.

A quarter of all the contraceptive users in each of the three age groups reported a decline in sexual desire following the start of use. Women using hormonal contraceptives reported this decrease more often than women using hormone-free contraceptives $(p=0.001)$ (Table 2).

Multiple regression analysis showed that the decrease in sexual desire could not be explained by age, educational level, number of children, depression or overweight (BMI $>25 \mathrm{~kg} / \mathrm{m}^{2}$ ). The only variables found to correlate with experiencing a decrease in sexual desire were having a partner and/or using a hormonal contraceptive method (Table 3). Of those answering the questions regarding both current contraceptive use and experience of sexual desire, $24.5 \%(n=333)$ had either no partner or only occasional partners. The odds ratio (OR) of having decreased sexual desire in women using a hormonal contraceptive method was 2.39 (Table 3), whereas it was 0.98 when only taking into account the 333 women without a partner or with an occasional partner.

We analysed how the experience of reduced sexual desire affected the women's answers to several other questions related to contraceptive use and sexuality (Table 4). Forty-five percent of the women, irrespective of age or contraceptive method (those wanting to become pregnant excluded), wished to stop or change the contraceptive method they were 
using when they completed the questionnaire. The reasons for this are summarised in Table 5, which shows two groups: one, users of hormonal contraception; the other, users of hormone-free contraception.

Twenty-two percent of the women reported experiencing diminished sexual desire connected with a previous episode of use of hormonal contraception. Half of these women still used hormonal contraception during the period studied; the other half had changed to a hormone-free alternative. The OR for planning to stop or change a hormonal contraceptive because of reduced sexual desire was 8.16 (95\% confidence interval [CI] 6.65-10.1) for the 99 women who had previously changed contraception due to the adverse effect of an earlier episode of hormonal contraception, in relation to the 68 women who had not experienced any adverse effects.

Most of the hormonal contraceptive users (85\%) reported at least one positive effect of the method: these included reduced anxiety about having an unintended pregnancy (44\%), more regular and reduced bleeding (46-54\%), and reduced dysmenorrhoea (43\%). Positive effects on sexual desire and mood were rarer: $3 \%$ and $8 \%$, respectively.

Most women (93\% of hormonal contraceptive users) were generally satisfied with their method and about $75 \%$ had already used the method for more than 1 year at the time of the study. Despite long duration of use, the majority of the women using hormonal contraception during the study period had previously tried another hormonal contraceptive method, leaving only $9 \%$ as first-time hormonal contraceptive users.

Single questions in each of a very small number of questionnaires (1-3\%) were not answered. However, the question concerning current contraceptive use was answered by all but five women. Five multiple choice questions included as one possible choice the answer 'I do not use any contraceptive method', which was concordantly answered by almost all women, with only a small variation of $1.7 \%$.

\section{DISCUSSION}

\section{Findings and interpretation}

One in four young Swedish women in our study reported that the use of contraception had a negative influence on her sexual desire. The experience of diminished sexual desire was 
significantly more common among women using hormonal contraception (27\%) than among women using hormone-free contraception (9-11\%). This experience was reported just as often by women using COCs as by women using progestogen methods, including the LNG-IUS.

Only the fact of having a fixed partner and using hormonal contraception showed in the regression analysis to be independent variables associated with lower sexual desire caused by contraceptive method. Interestingly, among women without a partner, generally few reported a negative effect on sexual desire associated with contraceptive use and there was no significant difference within this group between hormonal and hormone-free methods. Sexual desire is an individual experience with a complexity of physical, emotional and interpersonal factors. According to Basson ${ }^{18}$, female sexual desire is largely driven by responsiveness to different stimuli and only to a lesser extent by spontaneous or innate desire. A plausible cause of our finding that partnership was a variable that predicted decreased sexual desire could be that changed sexual desire due to use of contraceptives is more likely to become evident for women living with a partner than for women not in a sexual relationship.

We found decreased sexual desire to be the most frequent adverse effect, reported alone or with other adverse effects, that prompted reconsideration of the contraceptive method by women using hormonal contraception. Overall, contraceptive users who experienced a decrease in sexual desire were almost twice as likely to reconsider their choice of method as were women without this experience. This also indicates the importance of decrease in sexual desire as a risk factor for discontinuation of contraception.

Health benefits and a high level of satisfaction with the method were experienced by most women and these seem to be the reasons that led most to continue using the same method for at least a year.

Our overall interpretation of the results is that there seems to be a small proportion of women who experience impairment of sexual desire to an extent that overrides their experience of the positive effects of contraception. This could motivate women either to change to a hormone-free alternative or to try another type of hormonal contraceptive. Probably a greater percentage of 28-year-old women compared with younger women wanted to become pregnant, explaining that contraceptive use differed between the three 
age groups. Condoms and the copper intrauterine device (IUD) used as primary methods were more common in the oldest age group, even among those in this age group who were nulliparous and had a partner, whereas LNG-IUS use did not differ between age groups. One interpretation could be that women who experience adverse mood and sexual effects eventually choose a hormone-free alternative, although these methods have a markedly lower Pearl Index. Due to the cross-sectional study design we cannot say whether these changes evolve with time or are just caused by observing three different cohorts.

\section{Strengths and weaknesses of the study}

An obvious weakness of our study is the cross-sectional design, which did not allow us to determine causality of any kind. On the other hand, we had a large sample of young women and the $50 \%$ response rate enabled us to obtain a fairly good overview of prevalence and associations.

Another weakness is the fact that our questionnaire had not been used in earlier studies and, despite validation before its use, its reliability could be questioned. Five different questions that included the choice 'not using any contraceptive method' were positively answered, with only a minor variation of $1.7 \%$, suggesting high internal validity. Our questionnaire did not include questions about the duration of the current relationship or an estimation of the quality of the relationship. This prevents us from making further analyses of our finding that having a partner was just as important as the use of hormonal contraception when it comes to experiencing decreased sexual desire.

Users of hormonal contraception who experience reduced sexual desire were overrepresented among women with a generally reduced level of desire, i.e. women never or almost never feeling desire. We cannot clarify how these factors are interrelated in our study, but a generally decreased sexual desire could be a potential source of bias in our results.

Since all the women in our study were able to understand Swedish very well, our study group did not perfectly match the ethnic make-up of the present Swedish population.

Unfortunately, the response rate in our study was low (49.5\%); therefore, the data must be interpreted with caution and the generalisability of our findings is partly restrained. 
Women with negative experiences of hormonal contraceptives may be more prone to answer a questionnaire on the subject and this might have biased the results of the present study. Declining response rates are now being reported in many surveys in Sweden and other Nordic countries. In Finland, the response rate for women aged 25-64 declined by $0.5 \%$ per year, from $85 \%$ in 1978 to $71 \%$ in $2002^{19}$. In a meta-analysis of 59 surveys, no clear relation was found between the rate of response and a non-response bias, indicating that the search for mechanisms that link non-response rates and non-response bias should focus on the level of individual measures and not on the level of the survey ${ }^{20}$.

In the present study the distribution of contraceptive use among women was similar to that in other observational studies ${ }^{1,21}$, despite our relatively low response rate. We can therefore expect our participants to be reasonably representative of the general female population in these age groups, at least regarding contraceptive use.

\section{Similarities and differences}

A systematic review recently reported a prevalence of $15 \%$ of impaired sexual desire in women using a $\mathrm{COC}^{22}$. The difference between our results and those of that review may be caused by different ways of asking about reduction in sexual desire. A specific question on reduced sexual desire in a questionnaire, which also asks for possible consequences of a decrease in desire, could generate a higher frequency of positive answers. There may also be a selection bias caused by a low response rate, in that women with negative experiences may be more prone to respond.

Experiencing adverse effects could cause reconsideration leading to plans to stop or change contraceptive method ${ }^{5,23,24}$. This is in line with findings by Burrow et al. ${ }^{13}$, who concluded that around $8 \%$ of hormonal contraceptive users stopped their contraceptive method due to adverse effects on sexual desire.

We found that women who had changed a hormonal contraceptive method because of a decrease in sexual desire had about an eightfold increased odds of considering stopping or changing their hormonal contraceptive method again, which is consistent with earlier

findings ${ }^{25}$. Recall bias must, however, be considered and the calculated OR should be interpreted with some caution. 
Women who used the LNG-IUS reported the same extent of decrease in sexual desire as that reported by users of other methods of hormonal contraception. This is in contrast to previous reports that LNG-IUS use was associated with improved sexual desire and decreased intercourse-related pain $^{26}$. This latter study had a selection of parous women with a median age of 39 years presenting with menorrhagia, who actively asked for intrauterine contraception. The women in our study, however, were all young and might have responded on the basis of an earlier experience of negative effects on sexual desire with a COC.

Only three out of the 47 LNG-IUS users in the present study had not previously tried another hormonal contraceptive method. Half of the 13 women who used the LNG-IUS and reported reduced sexual desire had experienced the same adverse effect earlier with another hormonal contraceptive method. In a small randomised clinical trial, Gingnell et $a l .{ }^{25}$ showed that women with subjective reports of previous COC-induced mood deterioration displayed depressed mood and mood swings when re-exposed to COCs.

\section{Relevance of the findings}

We consider our results relevant and important because even though COCs have been available for more than 50 years surprisingly little is known about the prevalence of adverse sexual effects and mood symptoms truly related to COC use. Furthermore, the sexual and psychological side effects of COCs have mostly been treated as secondary outcome measures ${ }^{6}$. The precise estimates of COC-related adverse mood symptoms are not available due to the lack of placebo-controlled trials. A Cochrane review stated that there is a need for more studies actually designed to reveal side effects, including psychological effects, as primary outcome measures ${ }^{27}$.

Our findings are relevant contributions to the discussion of the benefits and drawbacks of hormonal contraception.

\section{Clinical implications}

Our findings suggest that clinicians should address adverse sexual effects during counselling and be aware of the increased risk of poor compliance when women report a decrease in sexual desire while using hormonal contraception, including the LNG-IUS. 
Paying attention to young women's experiences of negative effects on sexual desire could in the longer term even raise the level of contraceptive compliance and thus the unquestionable overall health benefits of hormonal contraception.

\section{Unanswered questions and future research}

The question of causality between hormonal contraception and decrease in sexual desire remains unanswered: placebo-controlled randomised clinical trials will be needed to determine causality. In our study, LNG-IUS users reported decreased sexual desire to the same extent as all other users of hormonal contraception, which should be confirmed by further studies.

Further, qualitative studies are needed for a better understanding of the decision-making mechanisms of contraceptive choice and compliance in relation to adverse sexual effects. These studies should ideally also take partner relationship into account.

\section{CONCLUSION}

Whether there is a true causality between hormonal contraceptive use and a decrease in sexual desire remains uncertain. We can state, however, that in a Swedish setting, around $27 \%$ of women aged 22-28 years using any kind of hormonal contraception reported negative effects on sexual desire that they believed were caused by the method itself. This experience is a strong contributor to the risk of discontinuation with that contraceptive method. This is an important issue in the clinical setting. LNG-IUS users seem to report decreased sexual desire to the same extent as all other users of hormonal contraception, which requires confirmation in future studies. 


\section{REFERENCES}

1. Lindh I, Blohm F, Andersson-Ellström A, Milsom I. Contraceptive use and pregnancy outcome in three generations of Swedish female teenagers from the same urban population. Contraception. 2009;8(2):163-9.

2. Johnsson S, Pion C, Jennings V. Current methods and attitudes of women towards contraception in Europe and America. Reproductive Health. 2013;10:7.

3. Schindler AE. Non-contraceptive benefits of oral hormonal contraceptives. International Journal of Endocrinology \& Metabolism. 2013;11(1):41-7.

4. O’Neil-Callahan M, Peipert Jeffrey F, Qiuhong Z, et al. Twenty-four-month continuation of reversible contraception. Obsterics \& Gynecology. 2013;122(5):1083-91.

5. Stuart Jourdan E, Secura Gina M, Qiuhong Z, et al. Factors associated with 12month discontinuation among contraceptive pill, patch, and ring users. Obsterics \& Gynecology. 2013;121(2):330-6.

6. Poromaa I-S, Segebladh B. Adverse mood symptoms with oral contraceptives. Acta Obstetricia et Gynecologica. 2012;91(4):420-7.

7. Bancroft J, Graham CA. The varied nature of women's sexuality: unresolved issues and a theoretical approach. Hormones and Behavior. 2011;59(5):717-29.

8. Caruso S, Agnello C, Malndrino C. Do hormones influence women's sex? Sexual activity over the menstrual cycle. J Sex Med. 2014;11:211-21.

9. Wallen K. Sex and context: hormones and primate sexual motivation. Hormones and Behavior. 2001;40:339-57.

10. Lee M, Morgan M, Rapkin A. Clitoral and vulvar vestibular sensation in women taking 20 mcg ethinyl estradiol combined oral contraceptives: a preliminary study. J Sex Med. 2011;8(1):213-18.

11. Davis SR, Bitzer J, Giraldi A, et al. Change to either a nonandrogenic or androgenic progestin containing oral contraceptive preparation is associated with improved sexual function in women with oral contraceptive-associated sexual dysfunction. $\mathbf{J}$ Sex Med. 2013;10:3069-79.

12. Murphy PA, Brixner D. Hormonal contraceptive discontinuation patterns according to formulation: investigation of associations in an administrative claims database. Contraception. 2008;77(4):257-63. 
13. Burrows LJ, Basha M, Goldstein AT. The effects of hormonal contraceptives on female sexuality: a review. The Journal of Sexual Medicine. 2012;9(9):2213-23.

14. Davis AR, Castano PM. Oral contraceptives and libido in women. Annual Review of Sexual Research. 2004;15(1):305-28.

15. Shah MB. Contraception and sexuality. Minerva Ginecologica 2010;62(4 ):331-47.

16. Rosen RC, Brown C, Heiman J, et al. The Female Sexual Function Index (FSFI): a multidimensional self-report instrument for the assessment of female sexual function. Sex \& Marital Therapy. 2000;26:191-208.

17. McCoy N. The McCoy Female Sexuality Index. Quality of Life Research. 2000;9(1): $739-45$.

18. Basson R. Women's sexual dysfunction: revised and expanded definitions. CMAJ. 2004;10(172):1327-33.

19. Tolonen H, Helakorpi S, Talala K, et al. 25-year trends and socio-demographic differences in response rates: Finnish Adult Health Behaviour Survey. European Journal of Epidemiology. 2006;21(6):409-15.

20. Goves RM, Peytcheva E. The impact of nonresponse rates on response bias. Public Opinion Quarterly. 2008;72(2):167-89.

21. Sköld A, Larsson M. Contraceptive use during the reproductive lifecycle as reported by 46-year-old women in Sweden. Sexual \& Reproductive Healthcare. 2012;3:43-7.

22. Pastor Z, Holla K, Chmel R. The influence of combined oral contraceptives on female sexual desire: a systematic review. The European Journal of Contraception and Reproductive Health Care. 2013;18:27-43.

23. Sanders SA, Graham CA, Bass JL, Bancroft J. A prospective study of the effects of oral contraceptives on sexuality and well-being and their relationship to discontinuation. Contraception. 2001;64(1):51-8.

24. Brynhildsen J. Combined hormonal contraceptives: prescribing patterns, compliance, and benefits versus risks. Therapeutic Advances in Drug Safety. 2014;5(5):201-13.

25. Gingnell M, Engman J, Frick A, et al. Oral contraceptive use changes brain activity and mood in women with previous negative affect on the pill. A double-blinded, placebo-controlled randomized trial of a levonorgestrel-containing combined oral contraceptive. Psychoneuroendocrinology. 2013; 38(7):1133-44.

26. Bastianelli C, Faris M, Benangiano G. Use of the levonorgestrel-releasing intrauterine system, quality of life and sexuality. Experience in an Italian family planning center. Contraception. 2011;84:402-8. 
27. Maitra N, Kulier R, Bloemenkamp KW, et al. Progestogens in combined oral contraceptives for contraception. Cochrane Database Syst Rev 2004;3:CD004861 Update in Cochrane Database Syst Rev011;5:CD004861. 
Table 1 Background data of women responding to the questionnaire $(n=1851)$.

\begin{tabular}{|c|c|c|c|c|c|}
\hline \multirow[t]{2}{*}{ Variable } & \multicolumn{3}{|c|}{ Age group, $\%$} & \multirow[t]{2}{*}{ Total, \% } & \multirow[t]{2}{*}{$\chi^{2}(p$-value $)$} \\
\hline & 22 years & 25 years & 28 years & & \\
\hline $\mathrm{BMI}<25 \mathrm{~kg} / \mathrm{m}^{2}$ & 83.1 & 78.4 & 76.9 & 79.7 & 0.025 \\
\hline Non-smoker & 91.4 & 94.9 & 92.9 & 93.0 & 0.061 \\
\hline Exercises regularly* & 52.8 & 56.3 & 51.2 & 53.6 & 0.192 \\
\hline Postgraduate studies $* *$ & 70.5 & 79.9 & 80.2 & 76.5 & $<0.001$ \\
\hline Considers herself healthy & 88.7 & 89.9 & 89.4 & 89.3 & 0.782 \\
\hline Depression treatment $\dagger$ & 7.7 & 7.3 & 7.1 & 7.4 & 0.906 \\
\hline Nulliparous & 98.4 & 92.1 & 74.9 & 89.6 & $<0.001$ \\
\hline Ongoing pregnancy & 0.7 & 3.1 & 8.0 & 3.6 & $<0.001$ \\
\hline
\end{tabular}

*Defined as two or more times per week.

**Defined as ongoing or completed studies.

$\dagger$ Includes both medical and other forms of therapies. 
Figure 1 Current contraceptive use ( $n=1724$, excluding pregnant or breastfeeding women).

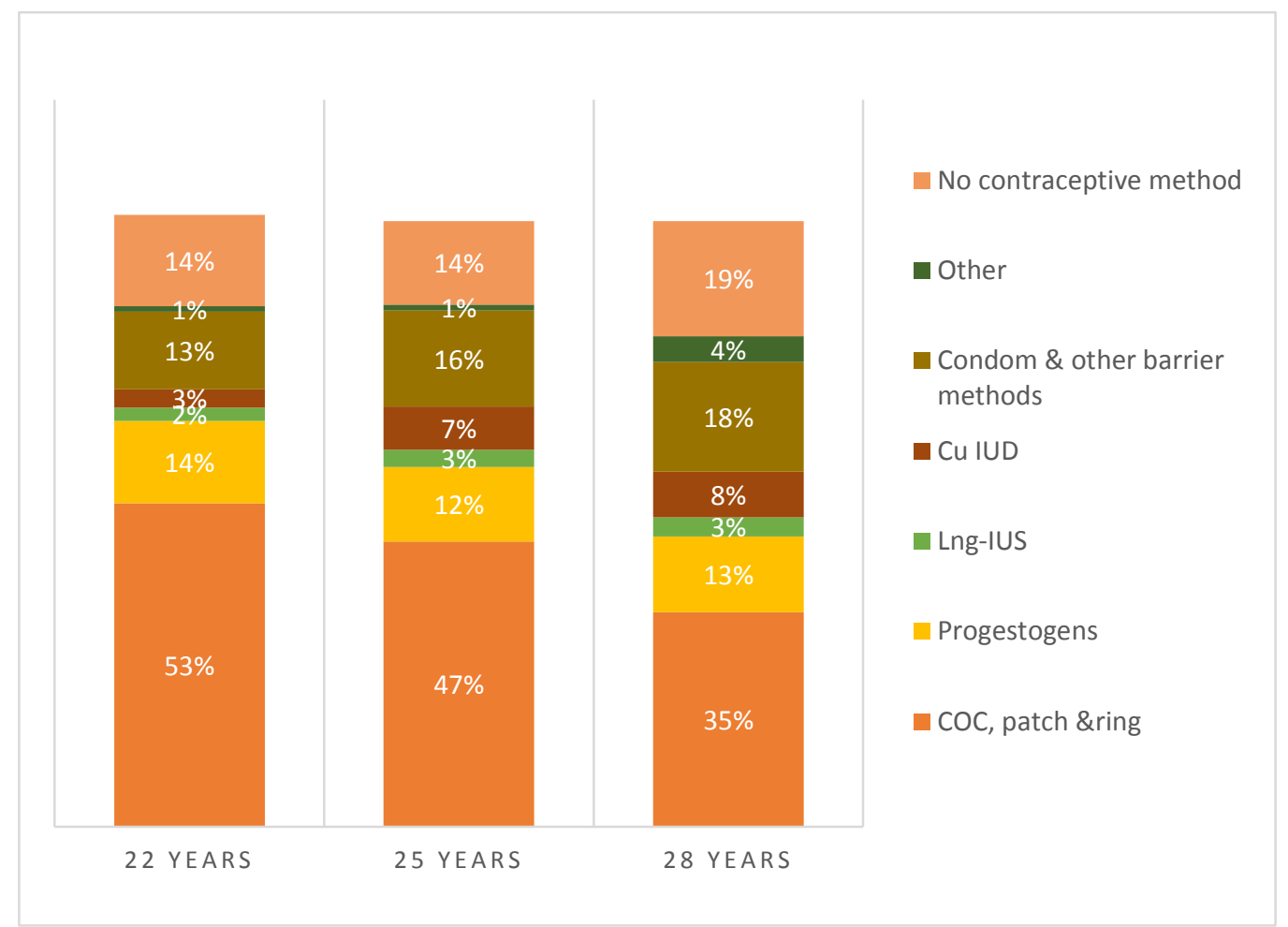

Lng-IUS = Levonorgestrel intrauterine system

Cu IUD = Copper intrauterine device

Other $=$ all other hormone free methods not elsewhere specified 
Table 2 Desire changes experienced by women using any kind of contraceptive method.

Women are grouped by the primary used method, i.e. women using condom as complement are not included in the condom group.

\begin{tabular}{|l|l|l|l|l|}
\hline \multirow{2}{*}{ Contraceptive method } & \multicolumn{2}{|c|}{ Sexual desire, $n(\%)$} & \multirow{2}{*}{ Total, $n(\%)$} & \multirow{2}{*}{$\chi^{2}(p$-value $)$} \\
\cline { 1 - 3 } & Unchanged/increased & Decreased & & \\
\hline COC, patch, vaginal ring & $560(73.0)$ & $207(27.0)$ & $767(100)$ & Reference \\
\hline Progestogens* & $159(72.6)$ & $60(27.4)$ & $219(100)$ & 0.90 \\
\hline LNG-IUS & $34(72.3)$ & $13(27.7)$ & $47(100)$ & 0.92 \\
\hline Copper IUD & $90(89.1)$ & $11(10.9)$ & $101(100)$ & $<0.001$ \\
\hline Condom & $192(83.1)$ & $39(16.9)$ & $231(100)$ & $<0.01$ \\
\hline Other** & $10(90.9)$ & $1(9.1)$ & $11(100)$ & $<0.001 \dagger$ \\
\hline Total & $1045(75.9)$ & $331(24.1)$ & $1376(100)$ & \\
\hline
\end{tabular}

*Includes POP, rod or injection.

**Includes all other contraceptive methods such as coitus interruptus, Billings Ovulation Method, safe periods, etc.

$\dagger$ According to Fisher's exact test. 
Table 3 Logistic regression of variables influencing the experience of impaired libido $(n=1284)$.

\begin{tabular}{|c|c|c|}
\hline Variable & OR $(95 \% C I)$ & Adjusted OR $(95 \%$ CI $)$ \\
\hline \multicolumn{3}{|l|}{ Age (ref. 22 years) } \\
\hline 25 years & $1.24(0.93-1.65)$ & $1.30(0.96-1.78)$ \\
\hline 28 years & $1.20(0.87-1.66)$ & $1.48(1.03-2.12)$ \\
\hline Hormonal contraceptive* & $2.01(1.44-2.80)$ & $2.39(1.66-3.43)$ \\
\hline Having a partner** & $2.31(1.65-3.23)$ & $2.38(1.67-3.39)$ \\
\hline \multicolumn{3}{|c|}{ Education (ref. primary school) } \\
\hline Secondary school & $1.53(0.50-4.67)$ & $1.14(0.35-3.69)$ \\
\hline Postgraduate studies & $1.40(0.47-4.19)$ & $1.03(0.32-3.26)$ \\
\hline Paritył & $0.70(0.40-1.23)$ & $0.58(0.30-1.12)$ \\
\hline \multicolumn{3}{|c|}{ Weight (ref. BMI $<25 \mathrm{~kg} / \mathrm{m}^{2}$ ) } \\
\hline $25-30 \mathrm{~kg} / \mathrm{m}^{2}$ & $0.73(0.50-1.07)$ & $0.77(0.51-1.14)$ \\
\hline$>30 \mathrm{~kg} / \mathrm{m}^{2}$ & $1.04(0.55-1.98)$ & $0.80(0.39-1.68)$ \\
\hline Depression & $1.20(0.75-1.91)$ & $1.35(0.81-2.25)$ \\
\hline
\end{tabular}

*Women using contraceptives categorised by hormonal contraceptives or hormone-free contraceptives.

**Occasional partners not included.

$\dagger$ One or more children. 
Table 4 This table shows how women grouped by their experience of affected or not affected sexual desire answered to other variables in the questionnaire.

\begin{tabular}{|l|l|l|l|l|l|}
\hline Variable & $\begin{array}{l}\text { Decreased } \\
\text { sexual desire } \\
(n=331), n(\%)\end{array}$ & $\begin{array}{l}\text { Unchanged or } \\
\text { increased sexual } \\
\text { desire }(n=1045), n \\
(\%)\end{array}$ & $\begin{array}{l}\text { Total, } n \\
(\%)\end{array}$ & $\begin{array}{l}\text { Total } n \text { of } \\
\text { women } \\
\text { answering } \\
\text { each variable } \\
(n=1376),\end{array}$ & $\begin{array}{l}\chi^{2}(p- \\
\text { value })\end{array}$ \\
\hline $\begin{array}{l}\text { Wish to change or } \\
\text { quit }\end{array}$ & $238(72.8)$ & $408(39.5)$ & $646(47.5)$ & 1359 & $<0.001$ \\
\hline $\begin{array}{l}\text { Not satisfied with } \\
\text { contraceptive } \\
\text { choice }\end{array}$ & $79(24.3)$ & $76(7.4)$ & $155(11.5)$ & 1352 & $<0.001$ \\
\hline $\begin{array}{l}\text { Wish more desire } \\
\text { Never or almost } \\
\text { never feeling } \\
\text { desire }\end{array}$ & $105(36.7)$ & $175(18.0)$ & $280(22.3)$ & 1257 & $<0.001$ \\
\hline $\begin{array}{l}\text { Asked for side } \\
\text { effect counselling }\end{array}$ & $207(62.9)$ & $656(63.7)$ & $863(63.5)$ & 1359 & $<0.001$ \\
\hline $\begin{array}{l}\text { Exercising } \\
\text { (regularly*) }\end{array}$ & $182(55.0)$ & $584(55.9)$ & $766(55.8)$ & 1371 & NS \\
\hline NS, & $315(30.3)$ & $610(44.5)$ & 1372 & NS \\
\hline
\end{tabular}

NS, not significant.

*Defined as two or more times per week. 
Table 5 Reasons given by women considering changing or stopping their contraceptive method, grouped by hormone or hormone-free contraceptive method users. $\mathrm{N}=689$

\begin{tabular}{|l|l|l|l|}
\hline $\begin{array}{l}\text { Reason for wishing to } \\
\text { change or stop }(n=689)\end{array}$ & $\begin{array}{l}\text { Hormonal contraception } \\
(n=503), n(\%)\end{array}$ & $\begin{array}{l}\text { Hormone-free } \\
\text { contraception }(n=186), n \\
(\%)\end{array}$ & $\chi^{2}(p$-value) \\
\hline Planning pregnancy & $49(9.3)$ & $18(9.7)$ & $\mathrm{NS}$ \\
\hline $\begin{array}{l}\text { No need for } \\
\text { contraception }\end{array}$ & $64(12.7)$ & $12(5.7)$ & $<0.01$ \\
\hline Cost & $45(8.9)$ & $8(4.9)$ & $\mathrm{NS}$ \\
\hline Mood change & $108(21.1)$ & $7(1.5)$ & $<0.001$ \\
\hline Decreased sexual desire & $167(32.6)$ & $17(7.2)$ & $<0.001$ \\
\hline Weight gain & $64(12.3)$ & $3(1.0)$ & $<0.001$ \\
\hline Bleeding & $84(16.7)$ & $29(13.9)$ & $\mathrm{NS}$ \\
\hline Nausea & $19(3.6)$ & $1(1.0)$ & 0.03 \\
\hline Genital pain & $26(5.0)$ & $18(9.3)$ & 0.04 \\
\hline Discharge & $37(7.0)$ & $11(5.2)$ & $\mathrm{NS}$ \\
\hline Genital infections & $12(2.2)$ & $4(3.1)$ & $\mathrm{NS}$ \\
\hline Hirsutism & $6(1.2)$ & $0(0)$ & $\mathrm{NS}$ \\
\hline Acne & $51(9.9)$ & $3(1.5)$ & $<0.001$ \\
\hline Fear of adverse effects & $119(23.3)$ & $8(3.1)$ & $<0.001$ \\
\hline Difficult to use & $51(9.9)$ & $83(42.3)$ & $<0.001$ \\
\hline Other reason & $89(17.7)$ & $58(27.3)$ & $<0.01$ \\
\hline NS & & & \\
\hline
\end{tabular}

NS, not significant. 